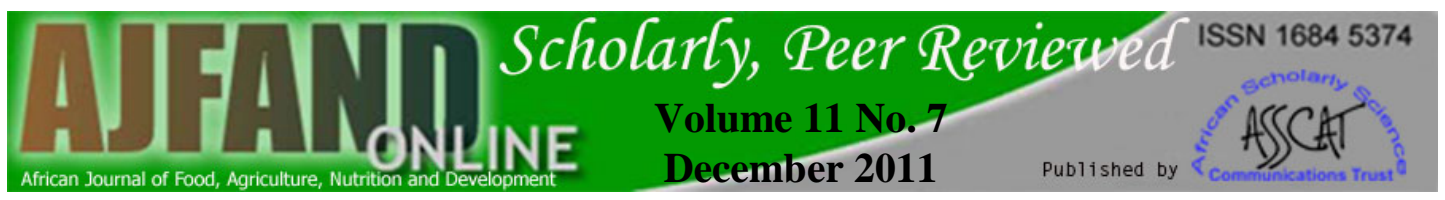

\title{
DIETARY ASSESSMENT IN AFRICA: INTEGRATION WITH INNOVATIVE
} TECHNOLOGY

\section{Wojtusiak $\mathbf{J}^{1}$, Gewa $\mathrm{CA}^{2 *}$ and LR Pawloski ${ }^{2}$}

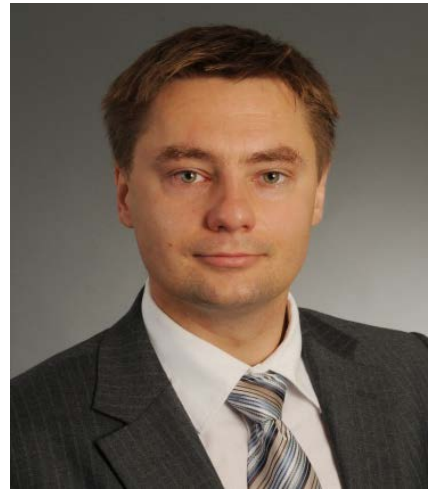

Janusz Wojtusiak

*Corresponding Author email: cgewa@gmu.edu

${ }^{1}$ Department of Health Administration and Policy, Machine Learning and Inference Laboratory Center for Discovery Science and Health Informatics, George Mason University, Fairfax, Virginia, USA

${ }^{2}$ Department of Nutrition and Food Studies, George Mason University, Fairfax, Virginia, USA 


\section{ABSTRACT}

Dietary assessment remains an important factor in understanding dietary practices and nutritional status and, helps inform policy and practice aimed at improving health and developmental outcomes in many populations. Adequate dietary intake is the basis of good health. Poor nutrition is a major limitation to growth and development throughout Africa. With poor access to clinics and hospitals, measuring dietary intake and nutritional status is one of the most efficient and informative means of understanding the health of a community. Further, the rise of both under- and overnutrition throughout Africa has created a double burden of disease, increasing the risk of both infectious and chronic diseases, making the need for a more specific dietary assessment critical for the prevention and treatment of nutrition related illnesses. In Africa and other less-developed regions, dietary assessment has often relied on respondents to recall types and amounts of foods consumed by populations of interest. Although use of recall methodology remains to be the most feasible strategy in these settings, there is great need to develop more creative and less dependent means of accurate dietary assessment, which are culturally suitable in impoverished regions of the world, and particularly among low-literacy populations. New technology-based methods that assist in more accurate and reliable dietary assessment are beginning to emerge. Most of these innovations are based on using technology to assist dietary recall. Such methods are shown to be effective, but still do not entirely remedy the challenges related to accurate and valid recall and measurement. The expanding use of such technology in these regions offers an opportunity for exploring the benefits and general acceptance of using technology to improve health. Thus, this paper reviews the literature concerning current diet assessment methods used in Africa as well as the implications for new and innovative methods and discusses the potential for utilization of technologically-based dietary assessment methods in Africa.

Key words: diet, innovative, technology, Africa, low-literacy 


\section{INTRODUCTION}

\section{Food insecurity and malnutrition}

Food insecurity and malnutrition remain high in many parts of Africa. According to the International Food Policy and Research Institute's (IFPRI) global hunger index (GHI), [an index that includes the proportion of people who are food energy deficient, prevalence of underweight in children under the age of five, and under-five mortality rate] only four countries on the continent have low levels of global hunger. Another three have moderate hunger levels while the remaining countries fall under serious, alarming, or extremely alarming hunger levels [1]. Stunting and wasting, common indicators of malnutrition, remain a significant problem in Africa, such that approximately $40 \%$ of children under five years of age are stunted, $21 \%$ are underweight and $10 \%$ are wasted [2]. While the prevalence of under-nutrition is strikingly high, the prevalence of overweight in Africa continues to rise [3, 4]. An assessment of available national and community-level survey data reveals a socioeconomic and demographic divide with wealthier nations, urban locations and women having higher levels of overweight and obesity [5,6]. Over $68 \%$ of women of reproductive age in Egypt and 55\% of women in South Africa are either overweight or obese [7]. Prevalence of overweight and obesity was 2-3 times higher among urban residents compared to rural residents in Kenya [5] and higher among urban female residents in Benin and Tanzania compared to their male urban counterparts [6, 8]. The rise of both under- and over- nutrition throughout Africa has created a double burden of disease increasing the risk of both infectious and chronic diseases, making the need for a more specific dietary assessment critical for the prevention and treatment of nutrition related illnesses [6, 9-11]. For example, for those with hypertension, a higher consumption of fat and salt may have severe consequences including cardiovascular diseases and stroke.

\section{Importance of dietary assessment in Africa}

Adequate dietary intake is the basis of good health. Poor nutrition, whether under- or over-nutrition is one of the major limitations to growth and development throughout Africa and the world [12]. With the limited access to clinics and hospitals, particularly in rural areas, dietary intake and nutritional status assessment provide critical information in understanding individual and community health status. One of the best uses of dietary assessment methods is for planning, developing, and evaluating nutrition intervention programs [13], and hence the need for tools that will allow for quick and accurate dietary estimates to support such programs. This paper reviews the literature concerning current dietary assessment methods used in Africa, as well as the implications for new and innovative methods, and discusses the potential for using increased technologically-based dietary assessment methods in Africa.

\section{REVIEW OF DIETARY ASSESSMENT METHODS}

\section{Traditional methods}

Traditional methods of dietary assessment include 24-hour recall, food frequency questionnaires, dietary journals, and observational studies. The authors conducted a detailed literature review in Medline, Pubmed, African Journals Online and Academic

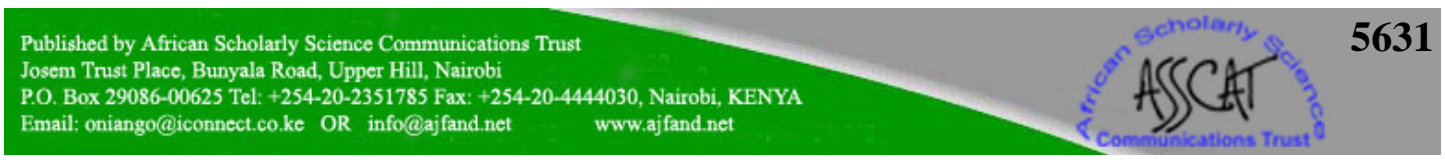




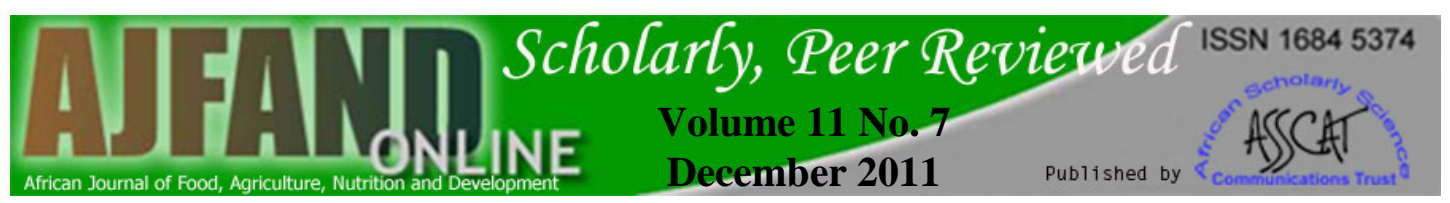

Search Premier and showed 24-hour recall and food frequency questionnaires to be most commonly employed among African populations. Furthermore, the authors conducted a detailed literature review to identify articles that reported on the validity of 24-hour recall and food frequency questionnaires among African populations. The following key words were used: validity, reproducibility, food frequency questionnaire, FFQ, 24-hour recalls, Africa, dietary validity and dietary assessment. These studies concerning dietary assessment in Africa are few however, and have been conducted primarily in South Africa, Mali, Kenya, Uganda, Malawi, Senegal, Ghana and Burkina Faso. While these studies examined the validity and reproducibility of these methods in specific regions of Africa, all methods had significant limitations (Table 1). The methods are commonly used because they are less costly, less time intensive, and there is a reduced chance of respondents changing their responses. However, such retrospective designs create challenges concerning the accuracy especially when respondents are required to remember specific types and quantities of foods, means of preparation and recipe and meal composition. For example, Par et al,[14] validated a food frequency questionnaire among adult men and women in Mali and found that the respondents had difficulties in recalling foods consumed in small quantities such as edible fats, meats/eggs and vegetables. MacIntyre et al,[15] showed that FFQ estimates of food groups that contributed substantial amounts to the respondents' diets had stronger and significant correlations with the weighed records' intake estimates .

\section{Observation and weighing methods}

Observation and weighing methods are not typically used beyond their purpose of comparison in validation studies. These methods are fairly difficult as they are considerably costly, time consuming and, in places of low literacy levels, the researcher is required to be present to weigh and record foods [16].

\section{The 24-hour dietary recall}

The 24-hour recall is the most common recall method in dietary assessment. It requires the participant to report all foods consumed in the past 24 hours [17]. This method requires the respondent to remember considerable detail of food types and amounts of foods often overlooked, for example, snacks and leftovers. There is also a tendency for over- or under-estimation of both macro and micronutrients. For example, in Kenya there were food replacements, food omissions, and poor estimations of food intake [18]. Further studies have shown an over-estimate of specific micronutrients among pre-school children and an under-estimate of macro and micronutrients among the elderly in Kenya [19]. One validation study in Malawi showed an under-estimate of energy and high-energy snacks and peripheral foods [20]. Another study in sub-Saharan Africa, compared the diets from two 24-hour recalls, and found that cultural eating styles limit the estimation of food intake as many people eat without utensils and consume foods from a common pot, creating greater challenges in estimating amounts and portion sizes [21]. Even with its limitations, the benefit of a 24-hour recall is that it asks respondents about all foods consumed, so that a better overall picture of macro and micronutrients can be assessed, unlike the food frequency questionnaires which focus only on specific 


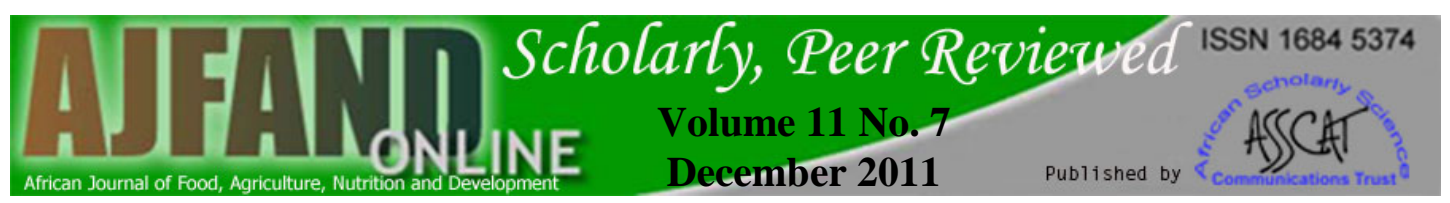

foods. Further, for researchers the intakes can be categorized, even though the absolute values might not necessarily be accurate.

\section{Food frequency questionnaire (FFQ)}

A food frequency questionnaire (FFQ) asks participants about specific foods consumed in a specific time frame. Generally, these questionnaires ask the subject to recall food intake from long periods of time such as seven or more days [22]. This type of questionnaire is useful for assessing specific types of foods and can quickly be analyzed as it is structured rather than open-ended as the 24-hour recall method. In its quantitative format, an FFQ can be used to estimate amounts of foods and nutrients consumed $[14,15]$. For example, the Women, Infants and Children (WIC) program's food frequency questionnaire asks mothers about WIC-recommended foods that include fruits, vegetables, iron-rich foods, calcium-rich foods, sweets, and sweetened drinks [23]. The WIC FFQ was developed to include foods of specific interest and would, therefore, not provide a general overall intake such as energy consumed, as many foods are not included in the food lists. In addition, most of these questionnaires are developed for specific populations or situations. For example, the WIC program developed their questionnaire specifically for pregnant women, mothers and children under five years of age. Other questionnaires have been designed to understand salt consumption among the elderly.

\section{Limitations in general}

In general, the dietary assessment methods typically used have many limitations. This literature review revealed the primary challenges related to recall and portion estimation. Throughout sub-Saharan Africa, where cooking is typically done by memory and taste, rather than with the use of standard measurements and recipes, estimating food intake with the use of standard measurements may not be culturally relevant. Further, questionnaires or interviews may need to be translated into the local language. The translation may not necessarily be accurate due to language differences and cultural interpretations. In addition, low literacy levels create greater challenges for participants responding to questionnaires or for community health workers conducting interviews.

Researchers continue to look into ways of improving recall and estimation methodologies. These have included the use of an interactive 24-hour recall, the multi-pass recall, and improved and relevant recall and estimation aids. The role of modern technology in improving dietary assessment is currently being tested in a few developed nations.

\section{Technology-based methods}

The most technologically driven dietary assessment methods currently used and validated include the use of web- based dietary records, as well as the use of personal digital assistants (PDAs) to support recall methods developed and used in developed countries. While the use of the web and computer- based assessment has created greater efficiency in terms of recording information, conducting analysis, and is more convenient for users, it has not necessarily improved the accuracy of the recall regarding the specific foods consumed and their amounts. A study by Riley et al.[24] 
examined the effects of a web-based food portion training program on food portion estimation . However, this program, while sensitizing participants to underestimating errors, appeared to lead to over-estimating errors. Computerized dietary assessment programs are the most commonly used technologies in dietary assessment. These programs rely on individuals accurately recording the types and the quantity of foods consumed. Their food composition data bases are also limited and do not include a diverse list of foods. Thus, there is a need for development of computer programs, which are culturally appropriate and require basic computer literacy of the participants [25].

Another study reported a growing preference for assessment tools using technology such as personal digital assistants or digital cameras. As children and adolescents in the United States of America become more exposed to computers and technology, research has shown they tend to prefer these means of assessment [26].

Recent publications were reviewed by Ngo et al. [27] concerning technology driven dietary assessment methods; the reviews were categorized into four groups: 1) computerized assessment, which included computer programs to assist with individual recall of food intake using three common methods: 24-hour dietary recall, food frequency and food diary methods, 2) personal digital assistants, which used the same methods as the computerized assessment; however, the PDA allowed participants to record their intake more immediately after consuming, 3) digital photography, which was used in combination with the computerized assessment and PDA methods and provided photographs to assist in recall of foods consumed, and 4) smart cards, which were used in dining facilities to assist in measuring food choices but not total quantity consumed. The findings indicate that computerized results were comparable to noncomputerized methods, with the tendency of lower accuracy for those not computer literate or for children. Personal digital assistants were shown to result in underreporting of food intake. Digital photography, however, conducted in dining facilities, was shown to be accurate and with direct visual observation the validity for this method was increased. This research concluded that there is a great need to improve the assessment of total caloric and micronutrient intake using such technologically driven tools [27].

One promising method to assist in improving the reporting of the quantity of foods consumed involves the use of spoken dietary records (SDR), which help individuals recall food intake when completing dietary intake questionnaires. These methods are useful in that food intake can be collected in real time with the use of cellphones [28]. However, currently these methods are not widely accessible nor have they been validated for the general population.

Finally, the use of photographic methods is another emerging means of collecting more accurate dietary intake information. While the photographs have been used to help participants recall their food intake, and by nutritionists for visual assessment [29], a new class of methods that relies on automated image processing and recognition is emerging [30]. 


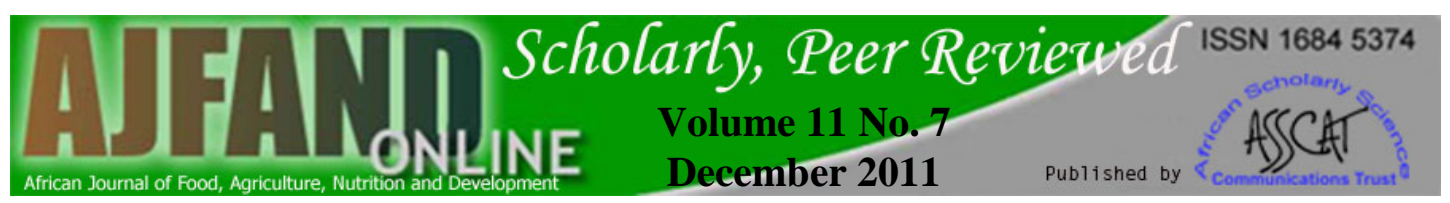

Overall, current technologically driven dietary assessment methods continue to be limited in terms of accuracy of recall and quantity of foods consumed. The next section describes how emerging technologies can impact dietary assessment, and identifies specific areas in which technologies can be used.

\section{Future Technologies in Dietary Assessment}

Dietary assessment can significantly benefit from the use of novel technologies, some of which are currently emerging in wealthier countries, and will soon emerge among developing nations. The most important improvement is through intelligent data collection and analysis, distributed processing, automated advising and reminder systems, and most importantly access to very large populations of people. These are achieved through wide access to intelligent systems [31], and cellular and data services provided by smartphones, personal computer and the internet and, it has become easier to collect data electronically, than to work with labor-intensive paper forms. This is possible, thanks to significant progress in mobile computing, artificial intelligence, and other areas that collectively aim at creating natural looking digital assistants that can interactively perform interviews and collect hard data from sensors [32].

Applications of innovative technologies to dietary assessments aim at: 1) measuring all consumed foods, 2) accurately recognizing contents and amounts of consumed foods, and 3) making the process easy and available to wide populations. In addition, innovative technologies are able to provide individualized feedback to users on the most appropriate choices for meals and dietary practices. Recent studies have indicated that innovative technologies, specifically cellphone usage as a form of dietary assessment can improve cooperation of the subjects and accuracy of the data. In addition, cellphone usage can provide detailed digital images that can be immediately transferred to a nutrient database for image analysis [26].

\section{Measuring all consumed foods}

One of the important drawbacks of recall methods discussed above is that people often forget about some of the foods they have consumed. This particularly applies to snacks, which are frequently not reported or to foods missed due to the timing, and palatability of consumed foods [33]. This situation can be improved by using technologies that range from simple reminder methods to complex measurement of physiological data.

Technological solutions to this problem include recognition that a person is eating and should record their food intake, reminders of which foods have been consumed throughout the day, assistance with recording the quantity of foods consumed, and measurement of household and individual food availability. One popular method is based on keeping a diary of consumed foods in a smartphone. Such diaries can be supplemented by pictures, which, however, are usually not automatically recognized and serve only as reminders of what was consumed [34].

Reminders encouraging users to record consumed foods can be periodically sent to cellular phones at regular meal times, or when an activity resembling eating is 
detected. Finally, the use of smart-home devices makes it easier to detect eating. For example, whenever a refrigerator or a food cabinet is opened, it is likely that food will be consumed or prepared. This can trigger a reminder in the form of voice, text message, or a simple sound indicating that a recording of foods consumed should be made [35].

It is possible to detect that a person is eating through a set of sensors located on the body. An example of such a method is discussed by Nishimura and Kuroda who proposed a solution based on using a wireless in-ear microphone able to detect chewing [36].

\section{Recognizing content and amount of meals}

To help people accurately report contents and amounts of consumed food, different technologies can be used. A method, which has recently gained popularity is based on taking photographs of consumed foods, then automatically analyzing them and estimating nutrient content [30]. Also, methods based on recording contents of meals at the moment of eating are possible because of advanced voice recognition systems. For many users, particularly those of lower literacy level, it may be beneficial to record voice descriptions of consumed foods. The voice can then be transformed into a structured form, understandable by computers by automatically finding key words that represent specific meals or ingredients, and nutrient content of the meal can be estimated. This can be done either with an intermediate step of transcription of entire recording into text and using text mining algorithms, or directly detecting specific words in speech.

Another method is based on barcode or receipt scanning, which is a simple but powerful method of identifying consumed food. It allows for the exact identification of products that are being consumed (including their specific nutrient contents). Scanning of barcodes and receipts is simple and can be done by currently available smartphone applications (FoodScanner app on iPhone) and use databases with hundreds of thousands of items. Scanned codes are then matched against a database of products for which their specific contents can be retrieved. However, in developing countries such methods using scanned codes might hold significant limitations as barcodes may not be readily available on most foods.

\section{Making the process easy and potentially available to large populations}

The use of technology allows for rapid collection and analysis of data, automated advising, and reminders. The process is easy, quick, and thus available to large populations of people. It takes a few seconds to take a photo of food, record a voice description of its content, or click on an icon representing that food in a clean graphical interface, in contrast to time-consuming questionnaires used in traditional recalls.

The future of dietary assessment methods will combine multiple methods of gathering data (images, barcode scanning, recalls, and intelligent refrigerators) to be analyzed by intelligent mobile personal assistants. The devices will collect data, provide 


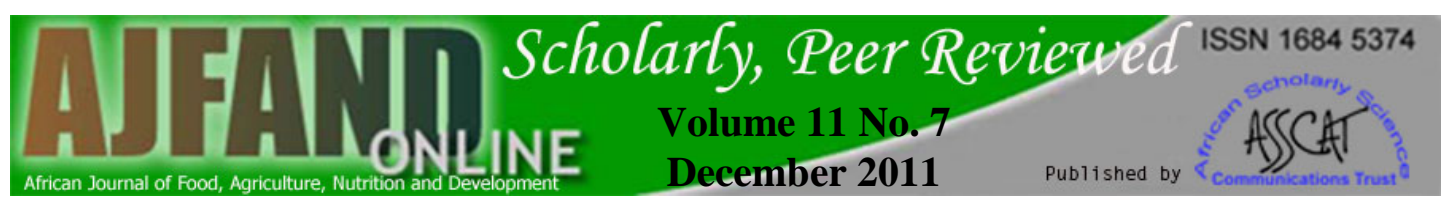

reminders and advice on how to best manage diets, and provide researchers and practitioners with wirelessly transmitted accurate data for dietary assessment.

Technologies described above assume that people want to provide accurate information about their dietary intake. No technology can account for the case when the provided values are deliberately falsified for cultural or other reasons. Innovative technologies in dietary assessment are meant to assist people, not to provide surveillance of their habits.

Significant growth in availability of technologies makes it possible for the described methods to go beyond boundaries of traditional dietary assessment, and makes many of the methods applicable with all populations. They may also ultimately be useful in estimating specific dietary behaviors and components of the diet, such as sodium and sugar consumption. The next section briefly describes technology growth in Africa, discusses how this growth opens the opportunity of using innovative dietary assessment methods, and highlights methods that are particularly suitable for use in rural regions of developing countries.

\section{The impact of Technology Growth in Africa on Dietary Assessment}

Cellular phones and mobile computing technologies are quickly emerging in Africa, including rural areas in which regular landline-based communication technologies are not available and mobile technologies provide the only advanced form of communication. The current statistics estimate 25 million cellular phone subscribers in Kenya by the end of 2010 with a yearly growth of around 5.5 million subscribers and with a penetration rate of approximately 63\% [37]. With the same penetration rate and growth of the mobile subscribers, carriers are expected to provide coverage to around 30 million subscribers by 2012, with a penetration rate increased to around $70 \%$ from the current level. The age group of the majority of cell phone users is estimated to be between 15 and 65.Cellular phones are also becoming an important means of communication in healthcare management [38]. Almost all cellular phone networks in Africa are GSM (the most popular mobile communication standard in the world), allowing, in addition to voice communication, sending and receiving text messages and in many places also data transmission.

One problem when using cellular phones is the need to recharge them, as electricity access remains fairly limited in rural Africa [39]. New technologies, however, emerge to improve accessibility of cellular phones. One such technology involves using solar-powered cellular phones that were introduced in Kenya in 2009 by the nation's largest operator, Safaricom [40]. Many other innovative solutions to the problem emerge, and include use of bicycles to charge phones [41]. Because of the cellular phone growth indicated above, the use of this technology can revolutionize dietary assessment in Africa. Particularly, the technology can provide access to large populations with low literacy levels (through use of imaging and voice technologies), reduce problems normally associated with recall methods, reduce cost of nutrition intervention and research activities, and most importantly provide individualized assessment and advice to people [42]. 


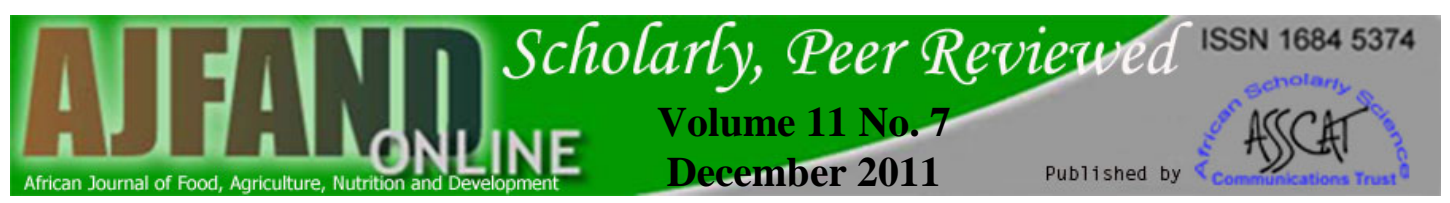

While not all mentioned novel methods for dietary assessment are feasible in rural African settings (those based on scanning of barcodes are obviously applicable only where packed foods are used), many other methods may provide strong impact. Specifically, methods based on automated analysis of photos taken by cellular phones, voice recognition, and use of simple graphical symbols representing foods seem to be the most suitable.

However, before advanced technologies for dietary assessment can be applied in rural Africa, several problems need to be overcome. First, cellular phones used in Africa are primarily basic models. These do not include smartphones; thus they are: limited in memory, the ability to run applications, and the ability to process data. This limits the possibility of using advanced methods of data analysis built into these devices. Also, data coverage is significantly smaller than voice coverage, not allowing for automated transmission of collected data to researchers. With extremely fast growth of technology and development of specialized applications, both problems can be overcome. Another significant issue related to the technology-based methods concerns their cost. Significantly, larger upfront investments are needed before dietary assessment can be done. This includes purchase of cellular phones and computer servers to collect data and training of participants. Development of software needed to collect data may also be costly, but software developed once may be adapted and reused in multiple studies. During the actual data collection the actual costs are expected to be relatively low, because there is less need for person-to-person interaction with participants and fewer researchers can be employed in the study. The actual cost analysis of the method is out of scope of this paper, but significant decrease of the cost of electronics as compared to labor may make the method feasible in the near future.

\section{CONCLUSION}

In this paper, the current major methods of dietary assessment have been reviewed and their specific limitations examined with special emphasis on methods in subSaharan Africa. These methods present significant challenges to collecting nutrient information as they rely on individual memory and the ability to quantify food intake. New technology-based methods are beginning to emerge, which assist in more accurate and reliable dietary assessment. Most of these innovations are based on using technology to assist recall. Such methods are shown to be effective, but still do not entirely remedy the challenges related to recall and measurement. Yet these technologies do have great potential to improve dietary assessment techniques, not only in wealthy nations, but in poorer regions of the world as well, including subSaharan Africa, where cellphone and communication technology along with its acceptance are rapidly growing. While still in an early phase, the movement toward newer and more innovative technologies will ideally improve the recognition of food content, the accuracy of amounts of foods consumed, and time and resources required to conduct nutritional analyses in a variety of settings and among diverse populations. 


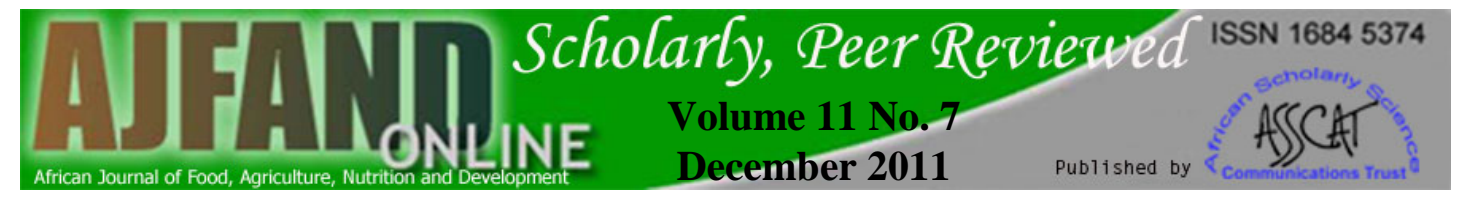

\section{ACKNOWLEDGEMENT}

This work was partially supported by the National Research University Project of

Thailand Office of Higher Education Commission 


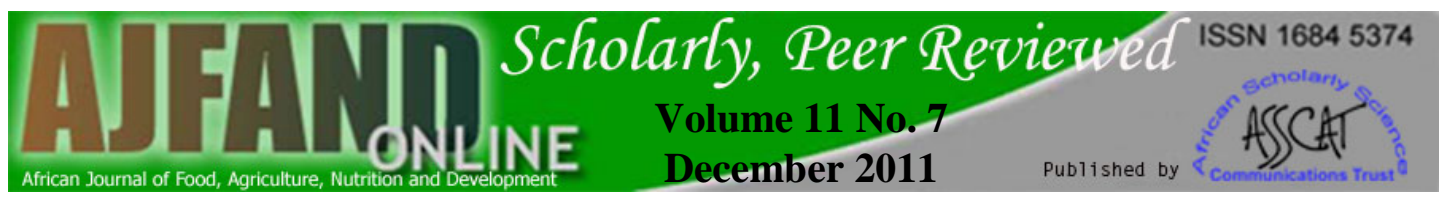

Table 1: Limitations of various dietary assessment methods utilized among populations in Africa

\begin{tabular}{|c|c|c|c|}
\hline Tested method & Author & $\begin{array}{l}\text { Population \& } \\
\text { Sample size }\end{array}$ & Referen \\
\hline Quantitative FFQ & MacIntyre et. $a l^{\lfloor 15\rfloor}$ & $\begin{array}{l}\text { North West Province } \\
\text { South Africa, ages } \\
\text { 15-65 years }\end{array}$ & $\begin{array}{l}\text { Weighe } \\
\text { records }\end{array}$ \\
\hline Quantitative FFQ & Parr CL et. al. ${ }^{\lfloor 14\rfloor}$ & $\begin{array}{l}\text { Western Mali, } 34 \\
\text { women and } 36 \text { men } \\
\text { ages } 15-45 \text { years. }\end{array}$ & Weigh \\
\hline Quantitative FFQ & Torheim et. al. ${ }^{\lfloor 4\rfloor}$ & $\begin{array}{l}\text { Western Mali, } 48 \\
\text { women and } 27 \text { men } \\
\text { ages } 15-59 \text { years }\end{array}$ & $\begin{array}{l}\text { Weighe } \\
\text { recalled } \\
\text { records }\end{array}$ \\
\hline “Sugar snacks” FFQ & Kiwanuka et. al. ${ }^{\lfloor 4\rfloor\rfloor}$ & $\begin{array}{l}\text { Kampala Uganda, } \\
614 \text { school children }\end{array}$ & $\begin{array}{l}\text { Five-da } \\
\text { behavio }\end{array}$ \\
\hline $\begin{array}{l}\text { Repeated 24-hour } \\
\text { recall }\end{array}$ & Ferguson et. al. ${ }^{\lfloor 46\rfloor}$ & $\begin{array}{l}\text { Greater Accra } \\
\text { Ghana, } \\
72 \text { children }\end{array}$ & Weigh \\
\hline $\begin{array}{l}\text { Repeated 24-hour } \\
\text { recall }\end{array}$ & Dop et. al. ${ }^{[45\rfloor}$ & $\begin{array}{l}\text { Dakar Senegal, } \\
45 \text { weanlings }\end{array}$ & $\begin{array}{l}\text { Qualitat } \\
\text { observa } \\
\text { weighe }\end{array}$ \\
\hline
\end{tabular}




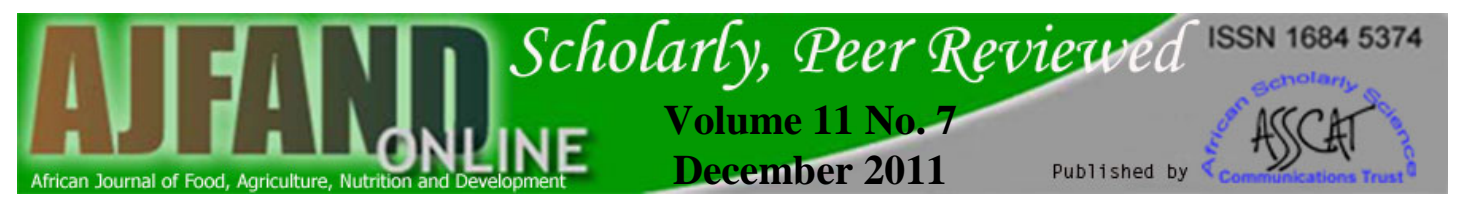

Repeated interactive Ferguson et. al. ${ }^{[20]}$ 24-hour recall

24-hour recall
Mangochi district Malawi, 60 pregnant women

Embu district Kenya, Weighed records 42 sets of school children and their mothers

Weighed records 24-hour recall underestimates most nutrient amounts.

Agreement levels lower for absolute nutrient estimates compared to energyadjusted nutrients, suggesting energy estimation errors.

24-hour recall underestimates most nutrient amounts. Difficulties in the recall of fruits and small quantity ingredients such as fat, added sugar and milk. 


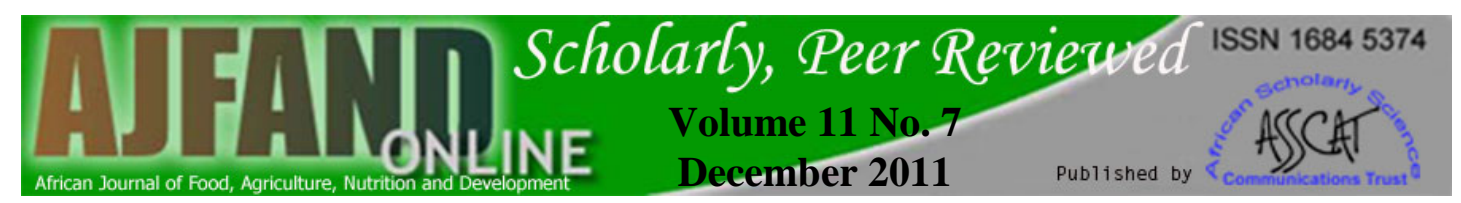

\section{REFERENCES}

1. IFPRI. Global Hunger Index. www.ifpri.org/publication/2009-global-hungerindex Accessed December, 2009.

2. UNICEF. Tracking progress on child and maternal nutrition: A survival and development priority. Www.unicef.org/publications/index_51656.html Accessed December, 2009.

3. de Onis $\mathbf{M}$, Blössner $\mathbf{M}$ and $\mathbf{E}$ Borghi Global prevalence and trends of overweight and obesity among preschool children. AJCN 2010; 5: 1257-1264.

4. World Health Organization (WHO). Global database on body mass index. http://apps.who.int/bmi/index.jsp Accessed December, 2010.

5. Christensen DL, Eis J, Hansen AW, Larsson MW, Mwaniki DL, Kilonzo B, Tetens I, Boit MK, Kaduka L, Borch-Johnsen $\mathbf{K}$ and $\mathbf{H}$ Friis Obesity and regional fat distribution in Kenyan populations: impact of ethnicity and urbanization. Ann Hum Biol. 2008; 35:232-49.

6. Njelekela MA, Mpembeni R, Muhihi A, Mligiliche NL, Spiegelman D, Hertzmark E, Liu E, Finkelstein JL, Fawzi WW, Willett WC and J Mtabaji Gender-related differences in the prevalence of cardiovascular disease risk factors and their correlates in urban Tanzania. BMC Cardiovasc Disord 2009; 9: doi:10.1186/1471-2261-9-30.

7. Demographic and Health Surveys (DHS). Countries Home. http://www.measuredhs.com/countries/ Accessed December 27, 2009.

8. Sodjinou S, Agueh V, Fayomi B and $\mathbf{H}$ Delisle Obesity and cardio-metabolic risk factors in urban adults of Benin: Relationship with socio-economic status, urbanisation, and lifestyle patterns. BMC Publ Hlth 2008; 8: doi:10.1186/1471-2458-8-84.

9. Caulfield LE, de Oni Ms, Blössner M and RE Black Undernutrition as an underlying cause of child deaths associated with diarrhea, pneumonia, malaria, and measles. Am J Clin Nutr 2004; 80:193-8.

10. BeLue R, Okoror TA, Iwelunmor J, Taylor KD, Degboe AN, Agyemang C and G Ogedegbe An overview of cardiovascular risk factor burden in subSaharan African countries: a socio-cultural perspective. Global Hlth 2009; 5:10 doi:10.1186/1744-8603-5-10.

11. Giday A, Wolde $\mathbf{M}$ and $\mathbf{D}$ Yihdego Hypertension, obesity and central obesity in diabetics and non diabetics in Southern Ethiopia. Ethiop J Health Dev 2010; 24: 145-147. 
12. Khongsdier $\mathbf{R}$ Under- and Over-nutrition with Special Reference to the Significance of Developmental Plasticity in Understanding Obesity and Associated Morbidity in Developing Countries. Human Ecology Special Issue 2005; 13: 43-52.

13. Taren D, Dwyer J, Freedman L and NW Solomons Dietary Assessment Methods: Where Do We Go From Here? Pub Hlth Nutr 2002; 5: 1001-1003.

14. Parr CL, Barikmo I, Torheim LE, Ouattara F, Kaloga A and A Oshaug Validation of the second version of a quantitative food-frequency questionnaire for use in Western Mali. Pub Hlth Nutr 2002; 5: 769-781.

15. MacIntyre UE, Venter CS and HH Vorster A culture-sensitive quantitative food frequency questionnaire used in an African population: 1. Development and reproducibility. Pub Hlth Nutr 2000; 4: 53-62.

16. Pittsburgh Mind-Body Center. Nutrition. http://pmbcii.psy.cmu.edu/core_c/nutrition.html Accessed February, 2010.

17. Gibson RS Principles of Nutritional Assessment. Oxford Press, 2005.

18. Gewa CA, Murphy SP and CG Neumann A comparison of weighed and recalled intakes for school children and mothers in rural Kenya. Pub Hlth Nutr 2009; 12: 1197-1204.

19. Kigutha $\mathbf{H}$ Assessment of dietary intake in rural communities in Africa: experiences in Kenya. Am J Clin Nutr 1997; 65: 1168S-72S.

20. Ferguson EL, Gadowsky SL, Huddle JM, Cullinan TR, Lehrfeld $\mathbf{J}$ and RS Gibson An interactive 24-hr recall technique for assessing the adequacy of trace mineral intakes of rural Malawian women: its advantages and limitations. Eur J Clin Nutr 1995; 49: 565-578.

21. Hudson GJ Food intake in a West African village, estimation of food intake from a shared bowl. Br J Nutr 1995; 73: 551-569.

22. Coulibaly A, O'Brien HT and I Galibois Validation of an FFQ to assess dietary protein intake in type 2 diabetic subjects attending primary health-care services in Mali. Pub Hlth Nutr 2008; 12: 644-650.

23. WIC. Texas Department of State Health Services Women Infants and Children Program. Texas Child Feeding Study 2008.

www.dshs.state.tx.us/wichd/nut/riskreport-nut.shtm Accessed January, 2010.

24. Riley WT, Beasley J, Sowell A and A Behar Effects of a web-based food portion training program on food portion estimation. J Nutr Educ Behav 2007; 39: 70-76. 
25. Probst YC and LC Tapsell Overview of Computerized Dietary Assessment Programs for Research and Practice in Nutrition Education. J Nutr Educ Behav 2005; 37: 20-26.

26. Boushey CJ, Kerr DA, Wright J, Lutes KD, Ebert DS and EJ Delp Use of technology in children's dietary assessment. Eur J Clin Nutr 2009; 63: S50-7.

27. Ngo J, Engelen A, Molat M, Roesle J, Garcia-Segobia $\mathbf{P}$ and L SerraMajem A review of the use of information and communication technologies for dietary assessment. Br J Nutr 2009; 101: S012-S112.

28. Lacson $\mathbf{R}$ and $\mathbf{W}$ Long Natural language processing of spoken diet records. AMIA Annu Sump Proc 2006; 454-458.

29. Martin CK, Hongmei H, Coulon SM, Allen HR, Champagne CM and SD Anton A novel method to remotely measure food intake of free-living individuals in real time: the remote food photography method. $\mathrm{Br} J \mathrm{Nutr}$ 2009; 101:446-456.

30. Zhu F, Mariappan A, Boushey CJ, Kerr D, Lutes K, Ebert D and E Delp Technology-assisted dietary assessment. Computational Imaging VI. 2008; 6814: $10-11$.

31. Cook DJ, Augusto JC and RJ Vikramaditya Ambient Intelligence: Technologies, applications, and Opportunities. Pervasive and Mobile Computing 2009; 5: 277-198.

32. Green N and D Scott Virtual Healthcare Interaction. Technical Report FS-0907. AAAI Fall Symposium in Arlington Virginia, 5-7 Nov 2009.

33. Higgs S, Williamson AC and AS Attwood Recall of recent lunch and its effect on subsequent snack intake. Physiol Behav 2008; 94: 454-462.

34. Fukuo W, Yoshiuchi K, Ohashi K, Togashi H, Sekine R, Kikuchi H, Sakamoto N, Inada S, Sato F, Kadowaki $T$ and A Akabayashi Development of a Hand-Held Personal Digital Assistant-Based Food Diary with Food Photographs with Japanese Subjects J Am Diet Assoc. 2009; 109:1232-1236.

35. Park SH, Won SH, Lee JB and SW Kim Smart home - digitally engineered domestic life Pers Ubiquit Comput 2003; 7: 189-196.

36. Nishimura $\mathbf{J}$ and $\mathbf{T}$ Kuroida Eating Habits Monitoring Using Wireless Wearable In-ear Microphone. Proceedings of 3rd International Symposium on Wireless Pervasive Computing, ISWPC 7-9 May 2008; 130 - 132. 


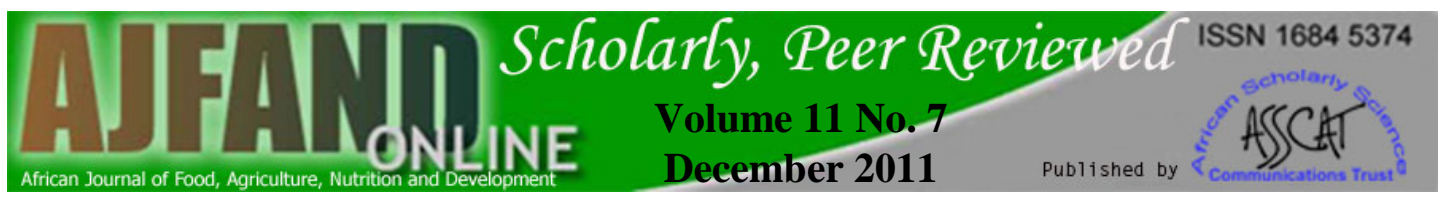

37. Communications Commission of Kenya. Quarterly Sector Statistics Report: $2^{\text {nd }}$ Quarter October-December 2010/2011.

http://www.cck.go.ke/resc/statcs.html Accessed July, 2011.

38. Lester $\mathbf{R}$ and S Karanja Mobile phones: exceptional tools for HIV/AIDS, health, and crisis management. Lancet Infect Dis 2008; 8: 738-739.

39. Madamombe I Energy Key to Africa’s Prosperity. Africa Renewal 2005; 18: 4.

40. Basu M and F Karimi Solar cell phones take off in developing nations.

Cnn.com/technology August 21, 2009

http://edition.cnn.com/2009/TECH/08/21/solar.cellphone/index.html.

Accessed December, 2009.

41. BBC. Pedal power for Kenya's mobiles July, 242009 http://news.bbc.co.uk/2/hi/africa/8166196 Accessed December, 2009.

42. Thompson FE and AF Subar Dietary Assessment Methodology. Secion1:A. National Cancer Institute. Bethesda, Maryland 2008.

43. Torheim LE, Barikmo I, Hatløy A, Diakité M, Solvoll K, Diarra MM and A Oshaug Validation of a quantitative food-frequency questionnaire for use in Western Mali Pub Hlth Nutr 2001; 4:1267-1277.

44. Kiwanuka SN, Astrøm AN and TA Trovik Sugar snack consumption in Ugandan schoolchildren: Validity and reliability of a food frequency questionnaire. Comm Dent Oral Epid 2006; 34:372-380.

45. Dop MC, Milan C, Milan C and AM N'Diaye The 24-hour recall for Senegalese weanlings: a validation exercise Eur J Clin Nutr 1994; 48: 643653.

46. Ferguson EL, Gibson RS and C Opare-Obisaw The relative validity of the repeated $24 \mathrm{~h}$ recall for estimating energy and selected nutrient intakes of rural Ghanian children. Eur J Clin Nutr 1994; 49: 241-252. 